\title{
Preemptive renal replacement therapy in critically ill patients?
}

\author{
Melanie Meersch, Alexander Zarbock \\ Department of Anesthesiology, Intensive Care and Pain Medicine, University of Münster, Münster, Germany \\ Correspondence to: Alexander Zarbock, MD. Department of Anesthesiology, Intensive Care and Pain Medicine, University of Münster, Albert- \\ Schweitzer-Campus 1, Gebäude A1, 48149 Münster, Germany. Email: zarbock@uni-muenster.de. \\ Provenance and Peer Review: This article was commissioned by the editorial office, Annals of Translational Medicine. The article did not undergo \\ external peer review. \\ Comment on: Tu GW, Xu JR, Liu L, et al. Preemptive renal replacement therapy in post-cardiotomy cardiogenic shock patients: a historically \\ controlled cohort study. Ann Transl Med 2019;7:534.
}

Submitted Apr 15, 2020. Accepted for publication May 11, 2020.

doi: $10.21037 /$ atm-2020-110

View this article at: http://dx.doi.org/10.21037/atm-2020-110

Renal replacement therapy is still the only available therapeutic option in the treatment of critically ill patients with acute kidney injury. Although firstly introduced several decades ago, there are still a lot of uncertainties regarding the optimal management of renal replacement therapy. Especially the question concerning the optimal time point for initiation has long been discussed and still remains unresolved. Hope was placed into the latest published large randomized-controlled trials, Artificial Kidney Initiation in Kidney Injury (AKIKI), Early versus deLayed Initiation of Renal Replacement Therapy in Critically Ill Patients with Acute Kidney Injury (ELAIN) and Initiation of Dialysis Early versus deLayed in Intensive Care Unit (IDEALICU) (1-3). However, the three trials failed to demonstrate similar findings and raised a storm of discussion. Despite large differences in study design (e.g., patient cohort, severity of illness and definition of timing), findings offer new perspectives. Going deeper through the results of these trials, it can be presumed that there might be a threshold of renal damage where the nephrons are largely damaged and survival improvement no longer possible. Whether an earlier initiation of renal replacement therapy at a stage with lower loss of total renal mass prior to renal failure in a special patient population (patients at very high-risk for dialysis requiring acute kidney injury) might be beneficial for patients' outcome has been indicated by the ELAIN trials but needs further investigation.

Recently, Tu et al. published the 'Preemptive renal replacement therapy in post-cardiotomy cardiogenic shock patients: a historically controlled cohort study' (4). This was a pre (retrospective)-post (observational) cohort study of patients undergoing cardiac surgery developing postcardiotomy cardiogenic shock with acute kidney injury. In the first phase of the trial, renal replacement therapy was started depending on life-threatening indications or the discretion of the treating physician. In the second phase, a 'preemptive renal replacement therapy' strategy was adopted with a much earlier starting time point of renal replacement therapy. The results not only demonstrate significant lower hospital mortality rates in the group with preemptive renal replacement therapy strategy $(38.0 \%$ vs. $59.2 \%$; $\mathrm{P}<0.01)$, but also enhanced renal recovery ( $4.1 \%$ vs. $19.4 \%)$ and a shorter time to renal recovery $(12 \pm 15$ vs. $25 \pm 15 \mathrm{~d} ; \mathrm{P}=0.042)$. Severity of illness and renal replacement therapy performance were not different between the two phases of the trial except the time point of initiation of renal replacement therapy.

There are some important factors that might be responsible for the different outcomes. Acute kidney injury is a systemic disease which affects different organ systems. Fluid overload has been shown to be associated with a worse outcome especially in patients with acute kidney injury (5). The higher the fluid overload the higher the mortality rates (6). In this study, patients treated with a preemptive strategy had significantly less fluid overload which consequently might have affected patients' survival. In addition, hemodynamic instability is known to be crucial for the development of acute kidney injury, for disease progression and renal recovery as well as for patients' outcome. Arterial pressures below a certain threshold leads to organ hypoperfusion and low oxygen supply. The resulting 
ischemia initiates inflammatory reactions and results in organ damage. Interestingly, patients of the preemptive strategy group showed significantly higher mean arterial pressure values and lower doses of vasopressors indicating that early renal replacement therapy treatment might attenuate inflammation and a further decline in organ function. It has already been demonstrated that an early renal replacement therapy treatment is associated with reduced interleukin-6 and interleukin-8 concentrations (2); pro-inflammatory cytokines which are associated with adverse outcomes (7). The results demonstrated by Tu et al. shows that an early initiation of renal replacement therapy leads to clinical benefits by controlling complications of acute kidney injury.

Of course, results should be interpreted with caution since this was a single-center before and after-trial. However, the initiation of renal replacement therapy will always be an individualized patient-adapted decision. Although we lack enough evidence, such an approach has already been successfully demonstrated for prevention of AKI and might therefore be imaginable for this setting. It is conceivable that early treatment in patients at very high risk for disease progression might be beneficial through early controlling harmful systemic effects of acute kidney injury. This is certainly not true for all patients with acute kidney injury but might be for the high-risk cohort. What intensivists need is a risk stratification concept to early detect patients at risk for disease progression and renal replacement therapy.

\section{Acknowledgments}

Funding: This work was supported by the German Research Foundation (KFO342/1; ZA428/18-1 to AZ, ME5413/1-1 to MM) and the Else Kröner Fresenius Stiftung (2018_A96 to $M M)$.

\section{Footnote}

Conflicts of Interest: Both authors have completed the ICMJE uniform disclosure form (available at http://dx.doi. org/10.21037/atm-2020-110). MM reports personal fees from FMC, personal fees from Baxter, personal fees from Astute Medical, outside the submitted work; AZ reports personal fees from FMC, personal fees from Baxter, personal fees from Astute Medical, outside the submitted work.

Ethical Statement: The authors are accountable for all aspects of the work in ensuring that questions related to the accuracy or integrity of any part of the work are appropriately investigated and resolved.

Open Access Statement: This is an Open Access article distributed in accordance with the Creative Commons Attribution-NonCommercial-NoDerivs 4.0 International License (CC BY-NC-ND 4.0), which permits the noncommercial replication and distribution of the article with the strict proviso that no changes or edits are made and the original work is properly cited (including links to both the formal publication through the relevant DOI and the license). See: https://creativecommons.org/licenses/by-nc-nd/4.0/.

\section{References}

1. Gaudry S, Hajage D, Schortgen F, et al. Initiation Strategies for Renal-Replacement Therapy in the Intensive Care Unit. N Engl J Med 2016;375:122-33.

2. Zarbock A, Kellum JA, Schmidt C, et al. Effect of Early vs Delayed Initiation of Renal Replacement Therapy on Mortality in Critically Ill Patients With Acute Kidney Injury: The ELAIN Randomized Clinical Trial. JAMA 2016;315:2190-9.

3. Barbar SD, Clere-Jehl R, Bourredjem A, et al. Timing of Renal-Replacement Therapy in Patients with Acute Kidney Injury and Sepsis. N Engl J Med 2018;379:1431-42.

4. Tu GW, Xu JR, Liu L, et al. Preemptive renal replacement therapy in post-cardiotomy cardiogenic shock patients: a historically controlled cohort study. Ann Transl Med 2019;7:534.

5. Garzotto F, Ostermann M, Martin-Langerwerf D, et al. The Dose Response Multicentre Investigation on Fluid Assessment (DoReMIFA) in critically ill patients. Crit Care 2016;20:196.

6. Woodward CW, Lambert J, Ortiz-Soriano V, et al. Fluid Overload Associates With Major Adverse Kidney Events in Critically Ill Patients With Acute Kidney Injury Requiring Continuous Renal Replacement Therapy. Crit Care Med 2019;47:e753-60.

7. Simmons EM, Himmelfarb J, Sezer MT, et al. Plasma cytokine levels predict mortality in patients with acute renal failure. Kidney Int 2004;65:1357-65.

Cite this article as: Meersch $M$, Zarbock A. Preemptive renal replacement therapy in critically ill patients? Ann Transl Med 2020;8(16):978. doi: 10.21037/atm-2020-110 